\title{
Improving Structural Designs with Computer Programming in Building Construction
}

\author{
Adu Michael $\mathrm{K}^{1}$, Abe Omoloye $\mathrm{E}^{2}$ \\ ${ }^{1}$ Computer Science Department, Federal Polytechnic, Ado-Ekiti, Nigeria \\ ${ }^{2}$ Civil Engineering Department, Federal Polytechnic, Ado-Ekiti, Nigeria
}

\begin{abstract}
The scope of civil engineering is wide and the application of computer is not put to use as expected even among professionals in developing nations. This paper is an attempt at revealing methods available for application of computer as a tool which can tremendously improve the qualities of delivery especially utilization of user developed packages that are customized to suit a particular problem at hand. It exposes how computer programming can be used in detail designs and quick process to calculate complex force stresses in structures. It further brings to the fore its application in automation of structural designs in concrete, elicits explicitly how computer can accept data through programming and uses the data to provide information in the final analysis on total design load, moment generated and areas of main and distributed reinforcements to stair-case, landing to stairs and Slabs. 'Customized Computer Package' in this context implies a completely interactive software system with considerable dialogue between the user and the system before a solution is obtained. This is implemented using Object-Oriented FORTRAN programming language.
\end{abstract}

Keywords: Complex Force Stresses, Civil Engineering, Customized Computer Package, Object-Oriented FORTRAN, Structural Designs.

\section{Introduction}

Computer application has brought a paradigm shift in operations of virtually every professions including civil engineering. With the increasing size and complexity of information and its management in establishments all over the world, an increasing use is being made of computers, which can be regarded as the life wire of any engineering design especially in structural analysis and the data relating to them. The engineering details and data provided by clients are equally of importance. Structural engineering firms dealing with volumes of data daily and periodically need personnel to man these sensitive details. The civil engineering industries, particularly the structural engineering sections are preoccupied with a lot of activities with the single aim of getting economical and stable structures. These industries are places where complex action of forces and their reactions like wind loads, life loads, dead loads et cetera are analysed. It is not easy calculating or solving these complex analysis most of the time. It is therefore necessary to keep errors and fatigue in the process at minimal, as a result, the designers device various means of improving their services. Among these means is the use of computer for optimization and efficiency, Computers are devices that can perform calculation and logical operation at a great speed, without human intervention through the action of internally stored program [1]. Some of the attributes of the computer are responsible for their wide application in the engineering industries. These include its ability to handle a very large amount of data accurately, as long as the instructions given to it are reliable. Also the ability to perform task in repetition and perform hundreds of thousands of arithmetic operations at a phenomenal speed are added advantages[2]. However, only few engineering companies in developing nations have in recent time concentrated efforts on increased computerization of their operation with relative good success stories and occasional appreciation from clients. Apart from the use of conventional application packages, engineers are encouraged by the result of this work to improve upon their work through customized computer packages that they can develop on their own to handle their local structural design challenges by writing computer programs in any programming language of choice.

\section{Background Information}

There are three principal areas of application of computer in civil engineering depending on the task and intended method of achieving the task. These may be classified as: (a) using generic application software; (b) using specialized application software; and (c) programming.

\subsection{Generic Application Software}

Generic software is a class of program that is used to instruct a computer on how to perform a specified task. They are developed by powerful software development houses to cater for different areas of human endeavour. They are ready made, shrink wrapped software made by a software development company. Generic application software products include spreadsheets and equation solvers. They represent the useful middle 
ground between hand solutions and computer programming. Spreadsheet like Microsoft Excel as an example is easy to use and learn. They are structured and data are presented in tabular form. Input and output are easily done since any cell can be changed or displayed at any point in time. The inclusion of graphics capabilities makes it easy to prepare presentation-quality graphics and trends can be seen visually. Equation solvers, on the other hand, include MathCAD and MATLAB. With an equation solver, the user lists equations, gives values for the known variables and asks for a solution. The program then finds a direct solution or iterates to find a solution after the user supplies initial values. MathCAD worksheets are easy to create and results are immediately displayed. Other software products in this category include Microsoft Access for database purposes and CorelDraw for simple typesetting and drawings.

\subsection{Specialized Engineering Application Software}

Specialized engineering application software packages are commercial programs developed for specific problems in engineering. These programs are extremely powerful and realistic since they are written for practicing engineers. Specialized engineering application software products are appropriate for professional design classes such as reinforced concrete and steel design, structural analysis or construction management. These software products may be introduced as a supplementary tool to compare results using hand calculations. A clear advantage of using these software products, especially those with graphics and simulation is that one can visualize the behaviour of complex systems. There are a variety of software programs which are available for the different specialized disciplines of civil engineering. Most civil engineering practices in specialized subsets such as geotechnical engineering, structural engineering, transportation engineering, hydraulic engineering, environmental engineering, project and construction management and land surveying have one or more of these products that are developed specifically to solve problems in that area[3].

\subsection{Infrastructure Design}

III. Specific Areas of Application of Computer Software Products

One specific subset of application of computer applications is the infrastructure design. It works on the basis of the estimates of load, pressure, drainage and flow. Some software houses have attempted to provide design software catering for the variety of infrastructure design fields in an integrated manner. However, general-purpose software may be used in the same manner at a fraction of the cost of design software. It is often used by consulting engineers when the software provides insight to issues concerning crossing services as when a road design may have to accommodate the presence of underground pipes, as an example.

\subsection{Maintenance}

Another aspect of software programs utilized by civil engineers is not only for the use of designing site infrastructure, but also to maintain it. There are programs available which allow the engineer to monitor bridges for cracks and settlements, as well as water distribution networks for failing subsurface pipes through the use of sensors installed. This has created the ability for the engineers to eliminate some of the costs and liabilities associated with human inspectors. AutoCAD Civil 2012 offers the ability to streamline applications as well as other Autodesk programs, making it easier and cheaper for the engineers to work with others [3].

\section{Computer Programming}

Computer programming is a process of passing instructions to computer in order to perform a task. It involves activities such as analysis, understanding, and generically solving such problems resulting in an algorithm, verification of requirements of the algorithm including its correctness and its resource consumption, implementation (commonly referred to as coding) of the algorithm in a target programming language, testing, debugging, and maintaining the source code, and implementation of the build system. The algorithm is often only represented in human-parsable form and reasoned about using logic. Source code is written in one or more programming languages (such as $\mathrm{C}, \mathrm{C}++$, FORTRAN et cetera). The purpose of programming is to find a sequence of instructions that will automate performing a specific task or solve a given problem. The process of programming thus often requires expertise in many different subjects, including knowledge of the application domain, specialized algorithms and formal logic. Different programming languages support different styles of programming (called programming paradigms). The choice of language used is subject to many considerations, such as company policy, suitability to task, availability of third-party packages, or individual preference. Ideally, the programming language best suited for the task at hand will be selected.

\subsection{Improving Structural Designs with Application of Computer Programming}

A Computer Aided Design program with menu driven and user friendly interactive system that can guide civil engineer in an effort to design and construct various parts of a building is designed and implemented. This system is designed using Object Oriented FORTRAN programming language. The system consists of 
basically three levels, apart from the home display at activation point. The design phase involves transformation of the conceptual design into a detailed one for implementation. Designing a new system includes the input and output, database/file structure and other related matters. Parameters are defined and kept as a file[4]. The system tasks are defined based on data obtained from working drawing as the data elements. The output requirement from the data will be a general output of "loading to stairs ", "loading to landing" which in the final analysis that produces the areas of MAIN and DISTRIBUTED reinforcement and other specific requirements [5].
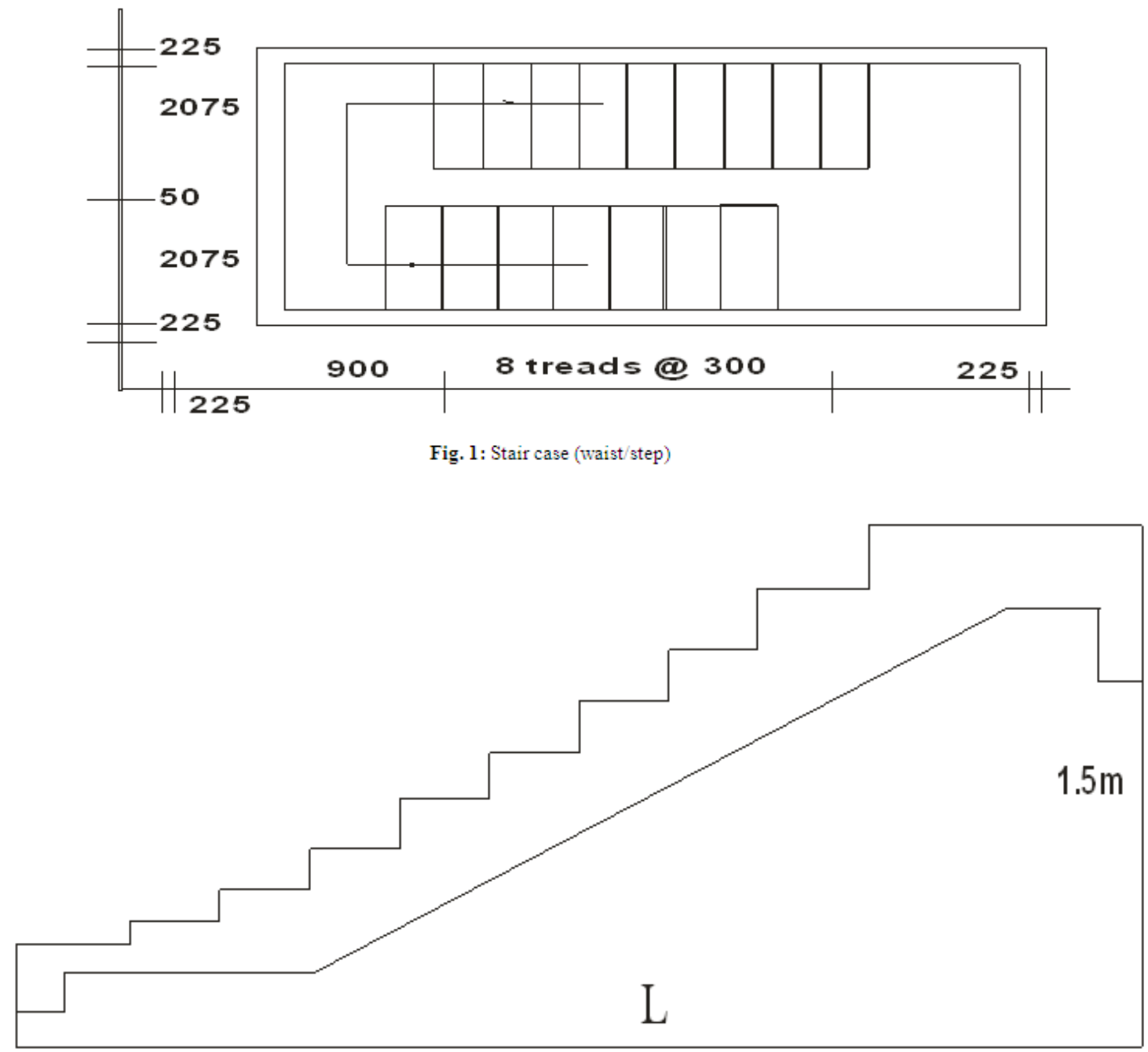

Fig. 2: Section through main stair

\section{Design Approach}

The following operational tasks are defined; Loading to landing, Loading to step /waist (stairs) and Loading to slabs. Each has subdivisions as follows: loading to landing (Moment of resistance determination $(\mathrm{mu})$, Areas of main and distributed reinforcement et cetera), loading to stairs (Moment of resistances determination (mu), Areas of main and distributed reinforcement determination), loading to stairs (Moment of resistances determination (mu), Areas of main and distributed reinforcement determination). The following documents are maintained in the system; Chart to check the value of LA (Lever Arm), Chart to check the number of reinforcement bars needed, Chart of tables containing; (a) Bending moments coefficients for slab spanning in two directions and (b) Concrete grade - Ultimate shear stress in beams, as well as any other relevant charts and tables. The design of the program was based on the steps taken to find the area of main reinforcement for a particular space and they followed the structure of methods (formula already approved by British Standard) of calculating them. All steps necessary for effective and efficient program delivery were followed. The program was checked and re-checked manually to make sure that all steps are touched and arranged in a logical order. After the computation is done by writing the source code in Object-oriented FORTRAN, it was also tested, debugged where necessary before put to use. The following figures show the various menu pages for operational details of the system. 


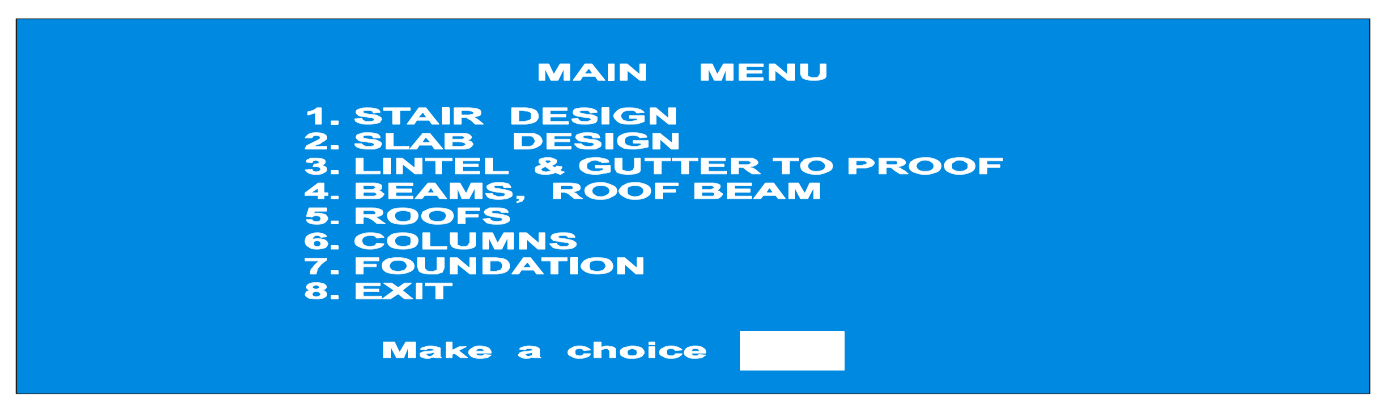

Fig. 3: Main menu

1. LOADING TO STEPMNAIST

2. LOADING TO LANDING

3. CANGEL OPERATION

Make a cholce

Fig. 4: loading menu

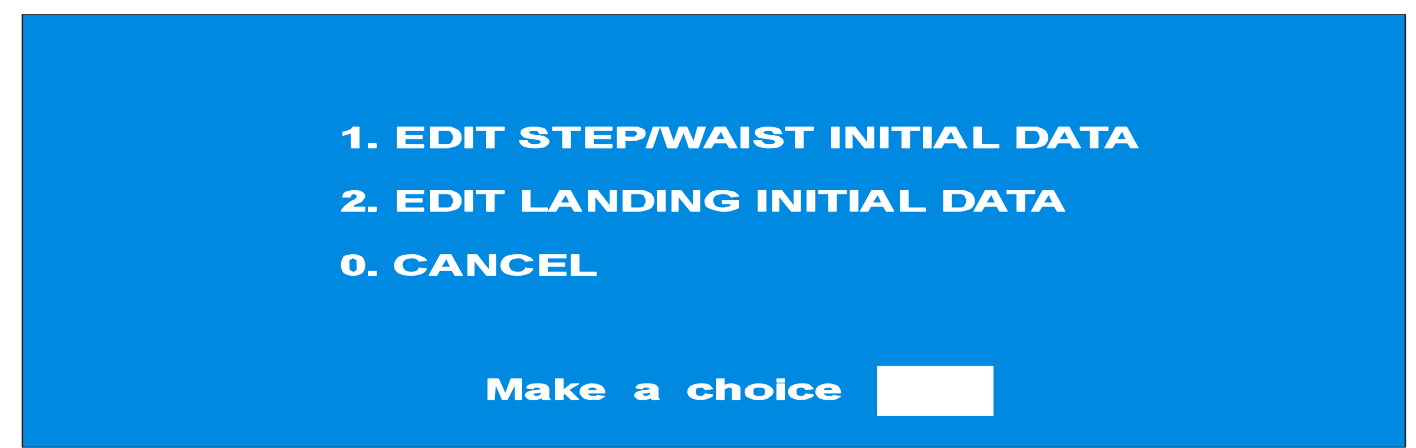

Fig. 5: Edit options

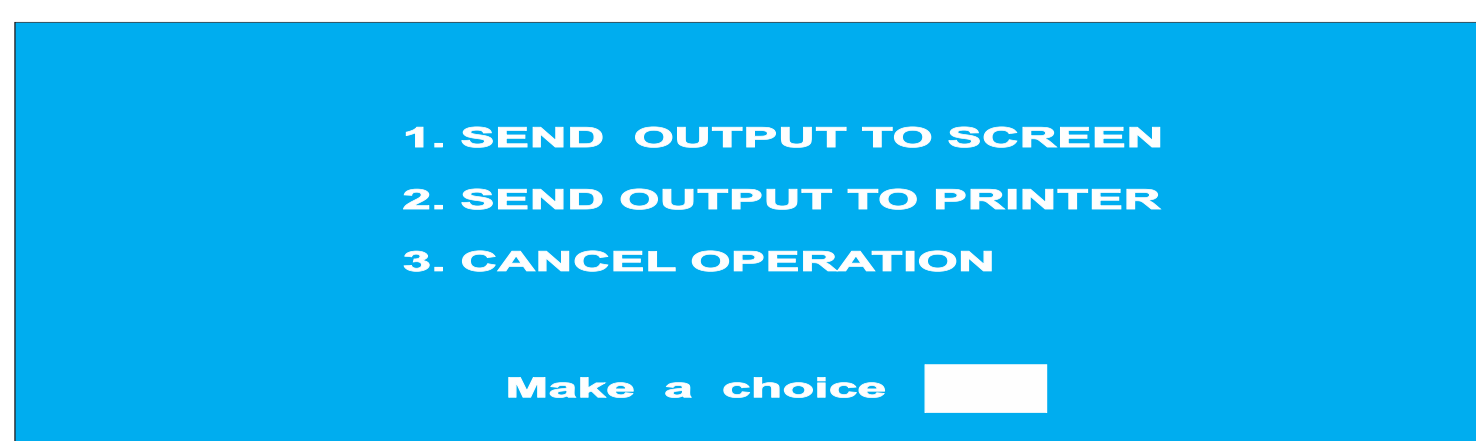

Fig. 6: Output options

\subsection{Stair Design}

\section{Experimental Results}

The determining parameters are as follows

No of Tread $T N O$

Length of Tread

TLEN

Length of support 1

SUPP1

Length of support 2

SUPP2

Height of support 1

HSI

Height of slab

HS

Cover to reinforcement

CR
8.000
.300
.225
.225
1.500
.150
.020 
Diameter of bar

Density of concrete

Life load

Characteristics cube strength of concrete

Characteristics strength of reinforcement

Width of landing

Thickness of landing

Riser height

Thickness of granno

Density of screed

Density of granno

No of risers

\section{DIAM}

DENCON

$L L$

$F C U$

$F Y$

$W L$

$T L$

$R H$

$T G$

$D S$

$D G$

$R N$
.025

24.000

1.500

25.000

250.000

.900

.150

.150

.025

19.000

23.000

9.000

3.5250

2.8302

19.0000

10.1887

5.4000

.6991

.7763

1.3800

16.2878

5.2875

31.2629

8.8480

.0256

Value to check for chart LA

$\mathrm{N}$

$\mathrm{M}$
Area of main reinforcement (AMR)

Area of distributed reinforcement (ADR)

\subsection{Loading to Landing Design}

The determining parameters are as follows

No of Tread

TNO

8.000

Length of Tread

TLEN

SUPP1

SUPP2

HS1

Height of support 1

$H S$

$C R$

DIAM

DENCON

$L L$

$F C U$

$F Y$

$W L$

$T L$

$R H$

$T G$

$D S$

$D G$

$R N O$

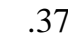

.23

Thickness of granno

Density of screed

Density of granno

No of risers

\subsubsection{Result}

Effective span for landing

ESL

Slab weight

SW $\quad 7.31$

Added weight of finishing

$\begin{array}{lr}\text { ADDFIN } & .50 \\ \text { GRANNO } & 1.17\end{array}$

Weight of granno

8.98 
Characteristic impose load Design

Add $1 / 2$ Total desing load

Moment

Chart value

Area of main reinforcement (AMR)

QK

DL

HALFLOAD

$\mathrm{M}$

LA

Area of distributed reinforcement (ADR) =
5.00

20.57

43.12

16.16

.046823240000

.672748

.225000

\subsection{Slab Design}

The determining parameters are as follows

\begin{tabular}{ll}
\hline Diameter of bar reinforcement & $D D B A R$ \\
Effective depth of slab & $D D S L A B$ \\
Thickness of slab & DTSLAB \\
Density of concrete & DENCON \\
Density of granno & $D D G$ \\
Density of screed & $D D S$ \\
Thickness of granno & $D T G$ \\
Characteristics impose load & DQK \\
Characteristics cube strength of concrete DFCU \\
Breadth of slab & DBSLAB \\
Thickness of screed & DTS \\
Characteristic strength of steel & DFY \\
Bread of the slab & $D L X$ \\
Length of the slab & DLY \\
Effective depth of slap & DSLAB \\
Self weight of slab & SELFWGT \\
Thickness of sand screed and cementSANDSCD \\
Weight of granno & GRANNO \\
Characteristic dead load & GK \\
Total design load & $D L$ \\
Moment of resistance of concrete & MU \\
Gradient of ly to lx & GRADT
\end{tabular}

.025

.120

.150

24.000

23.000

19.000

.025

2.500

25.000

1.000

.038

250.00

4.425

5.025

.1175

3.6000

.7220

.5750

4.8970

10.8558

51.77345000

1.1356

\subsubsection{Result for Two Dimensional Spanning}

Value 1 given by sx on the table

Value 2 given by sx on the table

$\begin{array}{ll}\text { SX1 } & .0440 \\ \text { SX2 } & .0330 \\ \text { SY1 } & .0370 \\ \text { SY2 } & .0280 \\ \text { MSX1 } & 9.3528 \\ \text { MSX2 } & 7.0146 \\ \text { MSY1 } & 7.8648 \\ \text { MSY2 } & 5.9518 \\ \text { RATX1 } & .1806 \\ \text { RATX2 } & .1355 \\ \text { RATY1 } & .1519 \\ \text { RATY2 } & .1150 \\ \text { ASX1 } & .3773 \\ \text { ASX2 } & .6238 \\ \text { ASY3 } & .9326 \\ \text { ASY4 } & .8957\end{array}$

Value 1 given by sy on the table

Value 2 given by sy on thetable

Bending moment at midspan on strips of unit $1 \mathrm{x}$

Bending moment at midspan on strips of unit $1 \mathrm{x}$

Bending moment at midspan on strips of unit ly

Bending moment at midspan on strip of unit ly

Ratio MSX1 TO MU

Ratio MSX2 TO MU

Ratio MSY1 TO MU

Ratio MSY2 TO MU

Area of tension reinforcement

Area of tension reinforcement

Area of tension reinforcement

Area of tension reinforcement

ASY4

.0330

.0370

0280

.3528

7.0146

7.8648

5.9518

1519

1150

3773

9326

.8957

\section{Comparing the Conventional Approach of Designing Structures in Building Construction with Computer Application by Programming}

The conventional approach to designing structures is like other manually operated system, full of limitations. Firstly, so much time is spent in calculating forces and loading in structures and also in building models in order to discover how stresses are distributed coupled with the inevitable long delays of generating results for detailer to work upon in order to produce working drawings. Moreover, because of the various data 
analysis to be done always, fatigue can set in, leading to inaccurate readings and substitution of data. The manual approach is especially not suitable for the application of designs that are urgently needed when time or duration of execution of the project is to be strictly adhere to. Some unscrupulous contractors use this time delay in manual approach to inflate contract sum, variation in cost to that obtained during tendering. The computer option takes care of these problems, though costly initially but more advantageous and even saves cost over time. Here the computer is particularly valuable in producing the calculations required in no time for immediate use and thereby eliminating the delay by the manual approach [6]. Lastly, the ultimate aim of generating the safest design load and minimum area of reinforcement for different structures and even the comparison of these involve a great deal of labour hour input and the final results may be untimely. The use of computer will facilitate these procedures. In order to eliminate or reduce to the barest minimum the nominal operational constraints in the structural design, the computerised system is set to achieve the following objectives: to design and create a database for the clients, to design and implement an application software that will make retrieval of information from the clients database file efficient, to improve the efficiency and level of productivity of the staff of the engineering industries which will be achieved by prompt and early computation of structural data for the design. Structural design of a building is a large system that may be divided into several other subsystems namely; Roof, Staircase, Slabs, Beams, Lintel, Columns and Foundations et cetera. For this work on computer aided structural design, Stairs, Landing and Slabs are considered. In all, the research work has brought to fore the following as major advantages of application of computer programming; Speedy processing of data, accurate storage of information, production of instant results to users (Civil Engineers ), reduction of designers overwork, motivation of designers for better performance and greater efficiency because the job is now less strenuous, easy generation of accurate result.

\section{Conclusion}

Computer Aided-Structural Design system is developed with the aim of solving most of the manual operational constraints in the design of structures. Such operational constraints as slow rate of data processing would be reduced to the minimum as soon as the system is put to use. A project begins with the recognition of a need, for example, the need to increase productivity or to increase effectiveness [7]. The need is examined and preliminary proposals raised and discussed. All aspects of the problem accessed. However there might not be a single 'right' solution but there may be several solutions, each with its own peculiar shortcomings, and the civil engineer uses his judgement to make professional recommendation of the solution to be adopted. Then the detailed design begins. Here the computer is particularly valuable in making the most rational calculation required. Attempt should be made to computerise other subsystems like steel structures, timber structures et cetera. It is not surprising that usefulness of a taught computer language in engineering course in particular, has come under close scrutiny. It is commonly assumed that an engineer need only to be able to use commercial software packages and is never likely to be involved in 'slogging away at computer codes'. From the outcome of this work, we are of the opinion that the complete reliance on packages is a mistake at this time. Almost invariably, packages need to be customized to suit the problem at hand or worse still ready-made application packages may not be available or, if they are, may be too expensive. It is pertinent therefore for civil engineers to be able to write codes customized to solve a particular task at hand as the case of structural designs in building construction made better with computer programming in this work.

\section{Acknowledgement}

We are very grateful to the management of Continuing Education Centre (CEC) of the Federal Polytechnic, Ado-Ekiti for enabling us to carry out the computer programming task at the Computer Laboratory of the Computer Science department at the Centre. Also, we appreciate logistic support granted by the Civil Engineering department of the institution.

\section{References}

[1]. O. C Akinyokun, Computers and programming using FORTRAN (New Era Commercial Press, Alagbaka, Akure, 1994).

[2]. K. K Aggarwal and S. Yogesh, Software Engineering (Third Edition, New Delhi: New Age International Publishers Limited 2004).

[3]. Wikipedia, Civil Engineering Software, The free encyclopedia

[4]. M. McCormick and G. Salvador. Numerical Methods in FORTRAN (Prentice Hall international Inc., London. 1990)

[5]. H, Mosley and H, Bungay. Reinforced Concrete Design (McMillan Education Ltd., London. Fourth Edition, 1990)

[6]. M. K. Adu. Computer Basis, Application and Programming (Onibonadura Publishers, Akure, 2004).

[7]. S.L. Pfleeger, Software Engineering, Theory and Practice (Prentice Hall, 2001). 